\title{
Blood flow in the brain venous blood vessels of children with cerebral palsy while using Bobath therapy
}

\author{
Bozhena O. Bukhovets ${ }^{1}$, Alexander P. Romanchuk ${ }^{2}$ \\ ${ }^{1}$ Children's Rehabilitation Center N. A. Boris Litvak, Odesa, Ukraine \\ 2 Odesa Medical Institute of the International Humanitarian University, Odesa, Ukraine, doclfc@ua.fm
}

\begin{abstract}
In the diagnosis of the causes of neurological disorders in children's with cerebral palsy is attached the results of Transcranial Doppler. Bobath therapy is most innovative and effective methods of physical rehabilitation. For the determination of brain blood flow of children of preschool age with various CNS lesions for the influence of the physical therapy using the Bobath's method, 35 children aged $4.1 \pm 1.1$ years were examined. That was the main group (MG). All of 72 procedures were conducted. There was also a control group (CG), the results of the brain blood flow had been studied and analyzed in 34 children aged $3.8 \pm 0.9$ years who were undergoing rehabilitation using standard methods. Traditional methods of physical therapy and the methods of the Bobath therapy have a significant effect on the brain venous blood flow. At the same time, the significance of individual methods of physical therapy is not convincing. The comparison of changes in blood flow using the Bobath therapy and traditional methods allowed identifying certain differences. The influence of the Bobath methods, on the first place, concerns the more optimal effect on the blood flow in the veins of the spine and the direct venous sinus. At the same time, changes in blood flow with traditional approaches are more convincing to the effect on blood flow in the internal jugular veins and veins of Rosenthal.
\end{abstract}

Keywords. Bobath therapy, blood flow, cerebral palsy.

\section{Introduction}

$\mathrm{T}$ ranscranial Doppler (TCDG) of the brain vessels is one of the leading methods for diagnosing CNS diseases that are used in combination with other methods of instrumental diagnostics (Echo-EC, EEG, CTG, MRI, etc.), based on its results in combination with the diagnosis of neurological status and psychophysical state, it is possible to determine the prognosis and to make a program of patients physical rehabilitation. (Abramova et al., 2014; Ashwal et al., 2004; Bode \& Buble, 1991). The significance is attached the TCDG results of the cerebral vessels in the diagnosis of the causes of neurological disorders in children's with cerebral palsy (Argyropoulou, 2010; Bukhovets \& Romanchuk, 2017; Dolgih \& Ivanichev, 2008; Evtushenko et al., 2014; Lavrik, 2004; Rosenkranz et al., 1990). Indeed, despite of the fact that the main factors of the development of cerebrospinal fluid are perinatal, a significant number of researchers consider the leading antenatal lesions of the fetus (37$60 \%$ ) against the background of hypoxia. Most often it is vascular-ischemic, or hemorrhagic lesions, in which the most vulnerable is the subcortical and periventricular white matter of the brain. The authors who conducted neuroimaging in lesions of children with cerebrospinal fluid showed that cortical subcortical atrophy is the result of arterialischemic, and periventricular - venous and hemorrhagic lesions (Dolgih \& Ivanichev, 2008; Lavrik, 2004; Fahey et al., 2016). Vascular lesions of the brain, as a factor in cerebral palsy, are put by other authors on the first place. Some authors have proven that the regulation of arterial and venous blood flow are related to the compensation of blood flow in the brain tissues, which occurs in conditions of increase or reduction of inflow and outflow of blood (Dolgih \& Ivanichev, 2008; Homar et al., 2004; Rosin, 2004). It shows the connection between venous and liquor pressures. Significant reserve capabilities of the brain venous system, which differs in the diversity structure of different caliber vessels, 
large capacity, the possibility of outflow in two directions, are also stated. That is, the method of TCDG, which investigates the brain arterial and venous system of at the extra and intracranial levels, can reveal their occlusion-stenosing lesions, deformations, anomalies of vascular development, arterial and venous aneurysms, arteriovenous malformations, venous circulatory disorders and their hemodynamic evaluation significance is important in predicting the possibility of compensation for lost functions (Ashwal et al., 2004; Dolgih \& Ivanichev, 2008; Knox \& Evans, 2002; Nyankovsky et al., 2017; Park \& Kim, 2017; Brooks et al., 2011). By analyzing the changes of TCDG in the main clinical forms of cerebral palsy, the authors (Dolgih \& Ivanichev, 2008; Lavrik, 2004) has shown that at spastic diplegia, neurophysiological disorders are more moderate than in other forms of cerebral palsy, and with double hemiplegia marked decrease in cerebral blood flow and increase intracranial pressure. At the same time, attention was paid to the fact that in spastic forms of cerebral palsy motor disorders are combined with a decrease in the linear velocity of blood flow the anterior and median cerebral arteries, which is accompanied by a significant increase in vascular resistance (Bode \& Buble, 1991; Evtushenko et al., 2014).

Among the existing innovative and effective methods of physical rehabilitation, Bobath therapy was established. It was created in the 30s of the XXth century by the practicing physiotherapist Bertha and the physician psychiatrist Carl Bobath. The concept of the method was substantiated in the 1940s, and in the 1950s, in addition to treating by the pose and implementing a complex of specialized physical exercises; the areas of speech therapy, gaming activity, selfcare and child care education with lesion of central nervous system (CNS) were enriched. However, scientifically grounded results that would indicate its impact on the state of children with CNS lesions is too little (Benito Garcia, 2015; Bortfeld, 1986; Bukhovets \& Romanchuk, 2014; Gialanella et al., 2004; Kozyavkin, 1992; Kraguljac et al., 2018; Varadharajulu et al., 2017; Vaughan-Graham et al., 2015).

The results of a preliminary analysis of changes in the parameters of TCDG using the Bobath method for children with cerebral palsy have allowed us to show that the most marked were intravenous circulation venous sinus (CVS). Namely, according to the algorithm developed by us for the estimation of violations, at the beginning of the course, only
$2.9 \%$ of children had deviations up to $70 \%$ increase, the variants of increase of blood flow were $150-190 \%$, which were recorded in $37,1 \%$ cases, even in $14.3 \%$ of children had an increase in blood flow of more than $190 \%$. That is, in more than half from all children there is a marked increase in blood flow to CVS. At the end of the course, most children $(62.9 \%)$ recorded changes within the $70 \%$ increase (Bukhovets \& Romanchuk, 2017). The obtained data prompted us to investigate the absolute parameters of blood flow changes in the brain venous system.

The purpose of this research was to determine how the venous brain blood flow of children with cerebral palsy will change due to the 6-month course of different approaches to physical rehabilitation, including using the Bobath method.

\section{Methods}

For the determination of brain blood flow (BBF) of children of preschool age with various CNS lesions for the influence of the physical therapy using the Bobath's method, 35 children aged $4.1 \pm 1.1$ years (at the beginning of the course) were examined. That was the main group (MG). All of 72 procedures were conducted. There was also a control group (CG), the results of the BBF had been studied and analyzed in 34 children aged $3.8 \pm 0.9$ years who were undergoing rehabilitation using standard methods (Bukhovets \& Romanchuk, 2017). In Table 1 the distribution of the children with lesions of the CNS before applying Bobath therapy in combination of physical therapy in the treatment of children's rehabilitation center named after Boris Litvak (Odessa, Ukraine) are shown.

During registering TCDG, probes of continuous and pulsed radiation of 2, 4 and $8 \mathrm{MHz}$ frequency were used. Measured linear velocity of blood flow (LVBF) - systolic, middle and diastolic - with the following indices: Stuart (systole-diastolic index) (ISD), Gosling pulsatory index (PI), resource Purselo index (RI) reflecting elastic-lens properties, vascular tone and their peripheral resistance. In order to characterize the changes in venous blood flow, parameters of internal jugular veins (IJV), vertebral venous plexus (VVP), Rosenthal veins (RV) and direct venous sinus (DVS) were analyzed, in which the most significant changes in blood flow were observed. The Mann-Whitney $U$ test for nonparametric statistics in determining the criterion of significance was used for the analysis of intergroup differences. 


\section{Table 1}

The distribution of children with CNS lesions in the form of cerebral palsy.

\begin{tabular}{lcc}
\hline \multirow{2}{*}{ The Form of CP } & MG & CG \\
\cline { 2 - 3 } & abs./\% & abs./\% \\
\hline Spastic diplegia & $18 / 51.4 \%$ & $16 / 47.1 \%$ \\
Double hemiplegia & $6 / 17.1 \%$ & $7 / 20.6 \%$ \\
Dextral or sinistral hemiparesis & $7 / 20 \%$ & $7 / 20.6 \%$ \\
Hyperkinetic form & $4 / 11.4 \%$ & $4 / 11.8 \%$ \\
Total & $35 / 100 \%$ & $34 / 100 \%$ \\
\hline
\end{tabular}

The course of Bobath therapy included: the provision of treatment using specialized child's body position, the reduction of the influence of pathological reflexes (ASSHT, lip reflex (snot reflex), sucking, search, Moreau, cross extensor reflex, etc.) on the musculoskeletal system and implementation, the complex of the exercises for the formation of elementary motor skills and the development of basic physical qualities (Bukhovets \& Romanchuk, 2014; Vargus-Adams \& Majnemer, 2014).

During the treatment, provision referred to "stacking" the limb or limbs, and sometimes to the entire body of the child in the defined position correction using specialized devices or their imitations. The main indication for the usage of this area are prevention or blocking the action of pathological reflexes that were result in abnormal positions of the joints and muscle groups and complicate the formation of basic motor skills; prevention of contracture and deformation formation; adaptation of the body to different positions relative to the gravity force (Bukhovets, 2016; Knox \& Evans, 2002).

Exhibition special exercises, which reduced or blocked the effect of pathological reflexes, has contributed to the formation of basic motor skills, etc. Carried out during physical activity, expert in physical rehabilitation and child were sent to inhibition (blockage) or eliminate abnormal motor patterns, stereotypes, promoted to more correct movements by stimulation, inhibition, facilitation, rotation, as well as the usage of positions that suppressed the action of pathological reflexes. When the inhibition was understood - blocking abnormal movements (tremors, associated and athetoid movements without dissociation), body positions (flexion or extension) and reflections that hinder the development of normal movement (corresponding to the biological age of the child). Facilitation is the facilitating the implementation of correct (normal) movements and the relationship between a child and a specialist in physical rehabilitation and facilitates the implementation of physiological movements. Facilitation includes proprioceptive, cognitive, perceptual and emotional aspects and is an active sensorimotor learning process. Stimulation is carried out with the help of tactile and kinesthetic stimuli necessary for the child to feel better the correct movements and positions of his own body in space (Knox \& Evans, 2002, Kozyavkin, 1992; VaughanGraham et al., 2015).

Exercises, which were carried out, were taken into account the individual abilities of the child. Standard approaches to the rehabilitation of preschool children with CNS lesions envisaged conducting lessons for physical therapy and pediatric massage.

\section{Results}

Sufficiently informative were the changes in blood venous circulation due to the influence of using methods Bobath therapy, which, in comparison with the traditional approach, had certain differences. Comparison of the effect on blood flow in the extraction vessels of the intracranial venous system, which according to many authors is decisive in the development of hemodynamic disorders in cerebral palsy. First of all, it refers to the blood flow in the internal jugular veins, which collect blood from the sinuses of the solid cerebellum, where blood flow from the surface veins of the brain, which in turn collects blood from the cerebral cortex. Changes in the system of left IJV in the MG children (Table 2) concerned a significant increase $(p<0.05)$ of LVBFmin from $7.81(6.95 ; 8.68)$ to $9.55(7.81 ; 10.40) \mathrm{cm} / \mathrm{s}$ with the fact that LVBFmax and LVBFaver significantly ( $p$ $<0.05)$ decreased from $52.9(48.6 ; 64.2)$ to 46.8 (41.6; $55.5)$ and from $30.3(21.7 ; 33.8)$ to 25.1 (22.5; 28.6) $\mathrm{cm} / \mathrm{s}$, respectively. The blood flow in the right IJV (Table 2) increased ( $p$ <.05) by LVBFmin and LVBFaver from $6.08(5.21 ; 8.68)$ to $7.81(6.08 ; 7.82)$ $\mathrm{cm} / \mathrm{s}$ and from $21.7(17.3 ; 28.6)$ to $26.9(20.8 ; 29.5)$ $\mathrm{cm} / \mathrm{s}$, respectively. Characteristic was decreased ( $\mathrm{p}$ $<0.05)$ of the vascular resistance in terms of Ri from $0.87(0.83 ; 0.88)$ to $0.81(0.79 ; 0.85)$ on the left, with 0.88 $(0.83 ; 0.89)$ to $0.84(0.82 ; 0.87)$ to the right and to RI from $1.72(1.58 ; 2.15)$ to $1.44(1.37 ; 1.71)$ to the right, which testified Significant improvement of venous current in the system of jugular veins. The influence of the traditional method of physical rehabilitation on blood flow in the IJV was somewhat different and 
related, in the first place, to a significant increase ( $\mathrm{p}$ $<0.01)$ LVBFaver on the left from $19.1(17.3 ; 20.8)$ to $23.8(22.5 ; 29.5) \mathrm{cm} / \mathrm{s}$ and its significant $(\mathrm{p}<0.05)$ increase to the right of $21.2(18.2 ; 25.1)$ to 25.1 (23.4; $27.7) \mathrm{cm} / \mathrm{s}$. At the same time, the resistance of blood flow to the left IJV also decreased significantly ( $\mathrm{p}$ $<0.01)$ from $0.87(0.84 ; 0.87)$ to $0.81(0.79 ; 0.84)$ for RI, from $1.89(1.75 ; 2.16)$ to $1.38(1.29 ; 1.62)$ for RI and the vessel tone from $7.40(6.30 ; 7.83)$ to $5.10(4.86 ; 6.25)$ for ISD, in contrast to the right, the decrease in vascular resistance in which was significant but less significant $(\mathrm{p}<0.05)$ for RI from $0.84(0.81 ; 0.85)$ to 0.81 (0.80; 0.85) for PI with $1.76(1.45 ; 2.00)$ to $1.37(1.21$; $1.52)$ and vascular tone $(\mathrm{p}<0.05)$ for ISD with $6.13(5$, $33 ; 6.86)$ to $5.27(4.89 ; 6.10)$.

Characterizing changes in the blood flow in the IJV can be stated that due to the rehabilitation measures in the MG and the CG there is a marked improvement in blood flow, however, which is more balanced in CG.

The results of the blood flow data in the VVP (Table 3) are supplemented with evidence of a pronounced decrease $(\mathrm{p}<0.01)$ of LVBFmax to the left of $14.7(13.8 ; 15.6)$ to $13.0(12.1 ; 13.8) \mathrm{cm} / \mathrm{s}$ using the Bobath method, while the traditional approach caused a significant increase $(\mathrm{p}<0.05)$ in LVBFmax from $12.1(11.2,15.6)$ to $13.9(12.1 ; 16.5) \mathrm{cm} / \mathrm{s}$. The same multidirectional effects of changes in blood flow to the right. The children in the MG have had
LVBFmin and LVBFaver decreased from 4.34 (3.47; $5.21)$ to $4.29(3.47 ; 4.34) \mathrm{cm} / \mathrm{s}$ and from $7.81(6.08 ; 9.55)$ to $7.80(6.08 ; 7.81) \mathrm{cm} / \mathrm{s}$, respectively, and in children CG their significant $(\mathrm{p}<0.05)$ increase from 4.34 (3.47; $6.08)$ to $5.65(4.34 ; 12.3) \mathrm{cm} / \mathrm{s}$ and $9.12(8.68 ; 9.55)$ to $9.55(7.81 ; 15.2) \mathrm{cm} / \mathrm{s}$ respectively. At the same time, the resistance and tone of the vessels VVP probably have not changed in both the MG and the CG. With the exception of a decrease $(p<0.05)$, the vascular resistance of the PI index to the left from 1.10 (1.00, $1.30)$ to $0.96(0.90,1.14)$. That is, the changes in blood flow of children in MG are more favorable. Significant blood flow changes of the CG children accompanied by an increase in LVBF, which may indicate a violation of the elastic-elastic properties of blood vessels in the studied area.

The effect on blood flow in RV (Table 4), which in the MG almost has not changed except for significant $(p<0.05)$ increase of LVBFmax to the left from 13.3 $(12.0 ; 13.5)$ to $13.5(12.0 ; 14.2) \mathrm{cm} / \mathrm{s}$, and of children in CG was characterized by a significant $(\mathrm{p}<0.05)$ reduction of LVBFmax, LVBFmin and LVBFaver on the left from $12.8(11.2 ; 15.0)$ to $11.2(9.8 ; 14.2) \mathrm{cm} / \mathrm{s}$, from $3.76(3.01 ; 6.02)$ to $3.01(1.50 ; 4.51) \mathrm{cm} / \mathrm{s}$ and from $7.90(6.77 ; 9.02)$ to $6.74(3.76 ; 9.02) \mathrm{cm} / \mathrm{s}$, respectively, and less significant (LVBFmin only) to the right of $4.14(3.01 ; 4.51)$ to $3.01(2,26 ; 4.40), \mathrm{p}<0.05$ was informative. It should be noted that according to the average data LVBFmax was within the age limit.

Table 2

Changes in blood flow in IJV of children (L - left, R - right) in the MG and the CG during the course of rehabilitation, $\mathrm{M}(25 ; 75)$.

\begin{tabular}{|c|c|c|c|c|c|}
\hline \multirow{2}{*}{ Parameters } & \multirow{2}{*}{ Side } & \multicolumn{2}{|c|}{ MG } & \multicolumn{2}{|c|}{ CG } \\
\hline & & At the beginning & At the end & At the beginning & At the end \\
\hline \multirow{2}{*}{ LVBFmax, $\mathrm{cm} / \mathrm{s}$} & $\mathrm{L}$ & $52.9(48.6 ; 64.2)$ & $46.8(41.6 ; 55.5)^{*}$ & $42.1(39.0 ; 48.6)^{\#}$ & $43.8(40.8 ; 45.4)^{\#}$ \\
\hline & $\mathrm{R}$ & $46.8(42.5 ; 54.7)$ & $45.1(39.9 ; 50.3)$ & $45.1(41.6 ; 52.9)$ & $43.2(38.2 ; 46.8)^{*}$ \\
\hline \multirow{2}{*}{ LVBFmin, $\mathrm{cm} / \mathrm{s}$} & $\mathrm{L}$ & $7.81(6.95 ; 8.68)$ & $9.55(7.81 ; 10.40)^{*}$ & $6.52(5.21 ; 8.68)^{\#}$ & $8.25(6.95 ; 9.55)^{\sharp *}$ \\
\hline & $\mathrm{R}$ & $6.08(5.21 ; 8.68)$ & $7.81(6.08 ; 7.82)^{*}$ & $7.81(6.95 ; 9.55)^{\sharp}$ & $7.41(6.08 ; 8.68)$ \\
\hline \multirow{2}{*}{ LVBFaver, cm/s } & $\mathrm{L}$ & $30.3(21.7 ; 33.8)$ & $25.1(22.5 ; 28.6)^{*}$ & $19.1(17.3 ; 20.8)^{\# \#}$ & $23.8(22.5 ; 29.5)^{* *}$ \\
\hline & $\mathrm{R}$ & $21.7(17.3 ; 28.6)$ & $26.9(20.8 ; 29.5)^{*}$ & $21.2(18.2 ; 25.1)$ & $25.1(23.4 ; 27.7)^{*}$ \\
\hline \multirow{2}{*}{$\mathrm{Ri}$} & $\mathrm{L}$ & $0.87(0.83 ; 0.88)$ & $0.81(0.79 ; 0.85)^{*}$ & $0.87(0.84 ; 0.87)$ & $0.81(0.79 ; 0.84)^{* *}$ \\
\hline & $\mathrm{R}$ & $0.88(0.83 ; 0.89)$ & $0.84(0.82 ; 0.87)^{*}$ & $0.84(0.81 ; 0.85)^{\#}$ & $0.81(0.80 ; 0.85)^{\# *}$ \\
\hline \multirow{2}{*}{$\mathrm{Pi}$} & $\mathrm{L}$ & $1.61(1.35 ; 1.89)$ & $1.52(1.49 ; 1.84)$ & $1.89(1.75 ; 2.16)^{\sharp}$ & $1.38(1.29 ; 1.62)^{\# * * *}$ \\
\hline & $\mathrm{R}$ & $1.72(1.58 ; 2.15)$ & $1.44(1.37 ; 1.71)^{*}$ & $1.76(1.45 ; 2.00)$ & $1.37(1.21 ; 1.52)^{\# *}$ \\
\hline \multirow{2}{*}{ ISD } & $\mathrm{L}$ & $6.30(5.60 ; 8.22)$ & $5.33(4.67 ; 6.71)^{*}$ & $7.40(6.30 ; 7.83)^{\#}$ & $5.10(4.86 ; 6.25)^{* *}$ \\
\hline & $\mathrm{R}$ & $7.71(5.25 ; 8.86)$ & $6.29(5.56 ; 7.86)$ & $6.13(5.33 ; 6.86)^{\#}$ & $5.27(4.89 ; 6.10)^{\# *}$ \\
\hline
\end{tabular}


Table 3

Changes in blood flow in VVP of children (L - left, R - right) in the MG and the CG during the course of rehabilitation, $\mathrm{M}(25 ; 75)$.

\begin{tabular}{lccccc}
\hline \multirow{2}{*}{ Parameters } & \multirow{2}{*}{ Side } & \multicolumn{3}{c}{ CG } \\
\cline { 3 - 6 } & & At the beginning & At the end & At the beginning & At the end \\
\hline \multirow{2}{*}{ LVBFmax, cm/s } & L & $14.7(13.8 ; 15.6)$ & $13.0(12.1 ; 13.8)^{* *}$ & $12.1(11.2 ; 15.6)^{\sharp}$ & $13.9(12.1 ; 16.5)^{\sharp *}$ \\
& R & $13.0(12.1 ; 14.7)$ & $13.8(12.1 ; 14.0)$ & $14.7(13.0 ; 16.5)^{\sharp}$ & $15.6(13.8 ; 17.7)^{\sharp}$ \\
LVBFmin, cm/s & L & $3.91(2.60 ; 5.21)$ & $4.34(3.47 ; 5.21)$ & $3.47(2.60 ; 5.21)$ & $5.21(4.34 ; 6.95)^{\sharp *}$ \\
& R & $4.34(3.47 ; 5.21)$ & $4.29(3.47 ; 4.34)^{*}$ & $4.34(3.47 ; 6.08)$ & $5.65(4.34 ; 12.3)^{\sharp * *}$ \\
LVBFaver, cm/s & L & $8.68(7.81 ; 9.55)$ & $9.50(7.81 ; 9.55)$ & $8.25(6.08 ; 11.20)$ & $9.43(6.95 ; 13.00)$ \\
& R & $7.81(6.08 ; 9.55)$ & $7.80(6.08 ; 7.81)^{*}$ & $9.12(8.68 ; 9.55)^{\sharp}$ & $9.55(7.81 ; 15.2)^{\sharp *}$ \\
Ri & L & $0.71(0.67 ; 0.75)$ & $0.68(0.64 ; 0.75)$ & $0.69(0.63 ; 0.79)$ & $0.71(0.64 ; 0.79)$ \\
& R & $0.71(0.62 ; 0.76)$ & $0.69(0.64 ; 0.75)$ & $0.72(0.59 ; 0.73)$ & $0.66(0.61 ; 0.75)$ \\
Pi & L & $1.10(1.00 ; 1.30)$ & $0.96(0.90 ; 1.14)^{*}$ & $1.07(0.85 ; 1.57)$ & $1.05(0.71 ; 1.38)$ \\
& R & $1.38(0.83 ; 1.50)$ & $1.17(1.00 ; 1.63)$ & $1.05(0.91 ; 1.22)^{\sharp}$ & $1.00(0.91 ; 1.50)^{\sharp}$ \\
ISD & L & $3.40(3.00 ; 5.33)$ & $3.10(2.80 ; 4.00)$ & $3.00(2.71 ; 4.33)^{\sharp}$ & $3.68(2.00 ; 4.67)$ \\
& R & $3.45(2.60 ; 4.25)$ & $3.20(2.80 ; 4.00)$ & $3.58(2.43 ; 3.75)$ & $2.68(2.43 ; 4.00)$ \\
\hline
\end{tabular}

$\# p<0.05$; \#\# - $p<0.01$ - between the MG and the CG data.

${ }^{*} p<0.05 ;{ }^{* *}-p<0.01$ - between the data at the beginning and the end.

Table 4

Changes in blood flow in RV in children (L - left, R - right) from the MG and the CG during the course of rehabilitation, $\mathrm{M}(25 ; 75)$.

\begin{tabular}{lccccc}
\hline \multirow{2}{*}{ Parameters } & \multirow{2}{*}{ Side } & \multicolumn{3}{c}{ MG } & \multicolumn{2}{c}{ CG } \\
\cline { 3 - 7 } & & At the beginning & At the end & At the beginning & At the end \\
\hline \multirow{2}{*}{ LVBFmax, cm/s } & L & $13.3(12.0 ; 13.5)$ & $13.5(12.0 ; 14.2)^{*}$ & $12.8(11.2 ; 15.0)$ & $11.2(9.8 ; 14.2)^{\sharp *}$ \\
& R & $13.5(12.0 ; 15.0)$ & $13.5(12.0 ; 14.2)$ & $12.8(10.5 ; 15.7)$ & $12.4(11.2 ; 15.0)$ \\
LVBFmin, cm/s & L & $3.01(2.26 ; 5.51)$ & $3.01(2.26 ; 5.26)$ & $3.76(3.01 ; 6.02)^{\sharp}$ & $3.01(1.50 ; 4.51)^{*}$ \\
& R & $3.76(3.01 ; 5.26)$ & $3.76(3.01 ; 4.51)$ & $4.14(3.01 ; 4.51)$ & $3.01(2.26 ; 4.40)^{\# *}$ \\
LVBFaver, cm/s & L & $8.27(6.77 ; 10.50)$ & $8.27(7.52 ; 9.78)$ & $7.90(6.77 ; 9.02)$ & $6.74(3.76 ; 9.02)^{\sharp}$ \\
& R & $7.52(6.77 ; 8.27)$ & $7.52(6.77 ; 9.78)$ & $7.52(4.51 ; 9.02)$ & $7.16(4.51 ; 9.02)$ \\
Ri & L & $0.75(0.64 ; 0.83)$ & $0.73(0.63 ; 0.80)$ & $0.68(0.67 ; 0.75)^{\sharp}$ & $0.74(0.69 ; 0.80)^{*}$ \\
& R & $0.71(0.61 ; 0.78)$ & $0.71(0.67 ; 0.76)$ & $0.75(0.67 ; 0.79)$ & $0.75(0.73 ; 0.86)^{\sharp}$ \\
Pi & L & $1.30(1.00 ; 1.36)$ & $1.20(1.00 ; 1.36)$ & $1.15(1.00 ; 1.29)^{\sharp}$ & $1.24(1.00 ; 1.44)$ \\
& R & $1.38(1.00 ; 1.60)$ & $1.22(0.92 ; 1.40)$ & $1.24(1.00 ; 1.83)$ & $1.39(1.20 ; 1.71)^{\sharp}$ \\
ISD & L & $4.00(2.75 ; 6.00)$ & $4.75(3.20 ; 5.50)$ & $3.13(3.00 ; 4.00)^{\sharp}$ & $3.75(3.25 ; 4.50)^{\# *}$ \\
& R & $3.50(2.57 ; 4.50)$ & $3.50(3.00 ; 4.29)$ & $3.71(2.67 ; 4.67)$ & $4.00(3.75 ; 5.00)^{\# *}$ \\
\hline
\end{tabular}

$\# p<0.05$ - between $M G$ and CG data.

${ }^{*} p<0.05$ - between the data at the beginning and at the end.

They also recorded a significant $(\mathrm{p}<0.05)$ increase in vascular tone by ISD from $3.13(3.00 ; 4.00)$ to 3.75 $(3.25 ; 4.50)$ and $3.71(2.67 ; 4.67)$ to $4.00(3.75 ; 5.00)$ left and right, respectively.

The influence on the blood flow in the DVS through which the outflow of venous blood from the vascular plexus and the inferior regions of the brain is carried out (Table 5) was characterized by more significant $(\mathrm{p}<0.05)$ changes in MG children, which related to LVBFmax reduction from $71.4(60.1 ; 81.2)$ to $62.4(54.1 ; 72.1) \mathrm{cm} / \mathrm{s}$ and LVBFaver with 37.6 (30.0; $39.1)$ to $32.3(28.5 ; 35.3) \mathrm{cm} / \mathrm{s}$ against the background of an increase in LVBFmin from $6.02(3.76 ; 7.52)$ to $6.77(6.00 ; 8.27) \mathrm{cm} / \mathrm{s}$. At the same time, in CG children, LVBFmax was also significantly decreased $(\mathrm{p}<0.05)$ from $70.3(52.6 ; 88.7)$ to $61.6(55.6 ; 72.9) \mathrm{cm} / \mathrm{s}$ 
and LVBFaver was $34.9(30.0 ; 42.1)$ to $31.6(30.0 ; 35.0)$ $\mathrm{cm} / \mathrm{s}$. At the same time, in the MG the resistance decreased from $0.92(0.91 ; 0.94)$ to $0.89(0.88 ; 0.92)$ and the blood vessel tone from $12.50(10.80 ; 16.20)$ to 9.09 $(8.09 ; 11.80)$ for the Ri and ISD indices respectively, whereas in the CG they remained intact.

\section{Discussion}

During using the Bobath method LVBFmax in the left IJV was reduced to the right, which showed a leveling of the asymmetry that was presented at the beginning. Similar changes were reported by LVBFaver, although, according to LVBFmin, blood flow asymmetry was maintained. It should be reminded that among the causes of IJV blood flow disturbance is the hypertonicity of the neck muscles, the narrowing of the bone channel at the site of the exit of IJV from the cranial cavity, the presence of arteriovenous shunts. The resistive index (RI) decreased significantly, but to the left it was significantly smaller. A certain asymmetry of changes was noted by the pulsatory index (PI), which significantly has decreased in the course on the right and was differed from the same on the left. The elastic properties of the IJV (ISD) have diminished both to the right and to the left, but the latter it has led to a certain asymmetry of change. At the same time, with the application of traditional approaches to physical therapy, the blood flow to IJV is symmetric, which is almost the same at the end of the course on the right and left. Particularly noteworthy the resistive (Ri) and the pulsator (Pi) indices that characterize vascular resistance are significant decreased. It shows that the Bobath method has a less positive effect on the blood flow in the IJV, unlike the traditional approach, and its techniques are not fully capable of optimizing the venous outflow from the surface brain vessels that collect blood from the cerebral cortex.

Considering the results of the dynamics in changes in the VVP during the using the Bobath method, it should be noted that the violation of venous blood flow in this area of the brain vessels system is associated with the narrowing of the bone channel in the distortion of the cervical spine, pathology of the connective apparatus of 1-2 cervical vertebrae, bone marrow twist and ventricular compression of the hyperplastic vertebral artery, which are most often associated with prenatal and perinatal anomalies and lesions. The obtained data has suggested some differences between the MG and the CG that are characterized by asymmetry due to an increase in blood flow by LVBFmax and LVBFmin on the left in the MG and on the right in the CG at the beginning of rehabilitation.

At the end of the Bobath course the alignment of LVBFmax was observed, which was achieved at the expense of a significant decrease to the left. At the same time, the traditional approach to physical therapy caused a significant increase in LVBFmax compared with baseline. It should be added as for LVBFmin in the CG, there was a significant increase compared to the initial level, which also exceeded the value of the MG. The rates of vascular resistance in the dynamics of physical therapy courses have not significantly changed except for the decrease of Pi on the left after using Bobath. In general, the results show that the Bobath method has a more positive effect on the venous blood flow in the vertebral veins associated with the bone-connective apparatus of the cervical spine.

\section{Table 5}

Changes in blood flow in DVS in children from the MG and the CG during the course of rehabilitation, $\mathrm{M}(25 ; 75)$.

\begin{tabular}{lcccc}
\hline \multirow{2}{*}{ Parameters } & \multicolumn{2}{c}{ MG } & \multicolumn{2}{c}{ CG } \\
\cline { 2 - 5 } & At the beginning & At the end & At the beginning & At the end \\
\hline LVBFmax, cm/s & $71.4(60.1 ; 81.2)$ & $62.4(54.1 ; 72.1)^{*}$ & $70.3(52.6 ; 88.7)$ & $61.6(55.6 ; 72.9)^{*}$ \\
LVBFmin, cm/s & $6.02(3.76 ; 7.52)$ & $6.77(6.00 ; 8.27)^{*}$ & $6.02(6.00 ; 7.52)$ & $7.14(5.26 ; 7.52)$ \\
LVBFaver, cm/s & $37.6(30.0 ; 39.1)$ & $32.3(28.5 ; 35.3)^{*}$ & $34.9(30.0 ; 42.1)$ & $31.6(30.0 ; 35.0)^{*}$ \\
$\mathrm{Ri}$ & $0.92(0.91 ; 0.94)$ & $0.89(0.88 ; 0.92)^{*}$ & $0.90(0.88 ; 0.92)^{\sharp}$ & $0.90(0.86 ; 0.91)$ \\
$\mathrm{Pi}$ & $1.79(1.49 ; 1.94)$ & $1.84(1.53 ; 1.93)$ & $1.87(1.67 ; 2.05)$ & $1.77(1.60 ; 2.31)$ \\
ISD & $12.50(10.80 ; 16.20)$ & $9.09(8.09 ; 11.80)^{*}$ & $9.55(8.45 ; 19.60)^{\sharp}$ & $10.50(7.45 ; 14.10)$ \\
\hline
\end{tabular}

$\# p<0.05$ - between $M G$ and CG data.

${ }^{*} p<0.05$ - between the data at the beginning and at the end. 
Violations of venous blood flow in RV are most often associated with venous discirculation at the level of 1-2 cervical vertebrae, increased intracranial pressure, congenital anomalies of the bone structure and articular and ligamentous apparatus. It became informative that the use of the Bobath method has not caused significant changes in the blood flow in the $\mathrm{RV}$, whereas the traditional use of traditional approaches has led to a significant increase in the tone in the veins, both right and left, and their elastic properties. Latter it occurred against the background of a significant decrease in LVBFmin and a certain asymmetry of blood flow, which was characterized by a decrease in LVBFmax and LVBFaver on the left. In this light, it can be assumed that the use of Bobath therapy is intuitive for blood flow to the RV, and traditional approaches to physical therapy have a predominantly negative effect on the blood flow latter.

Violations of venous blood flow in DVS of children with cerebral palsy, as it was shown in our publications before, were the most significant. However, the results we obtained have shown the effect of the Bobath methods is more significant than the traditional approaches to physical therapy. The children who have been used the Bobath method, LVBFmax and LVBFaver LVBFmin elevation have significantly decreased, which was accompanied by a significant decrease in vascular resistance and tone. While in the CG children effect has only affected LVBFmax and LVBFaver significantly. At the same time, it should be noted that only in several children in the MG and the CG, the rate of blood flow in PVA at the end of the course of physical therapy corresponded to the proper age value.

\section{Conclusions}

Traditional methods of physical therapy and the methods of the Bobath therapy have a significant effect on the brain venous blood flow. At the same time, the significance of individual methods of physical therapy is not convincing. The comparison of changes in blood flow using the Bobat therapy and traditional methods allowed identifying certain differences. The influence of the Bobath methods, on the first place, concerns the more optimal effect on the blood flow in the veins of the spine and the direct venous sinus. At the same time, changes in blood flow with traditional approaches are more convincing to the effect on blood flow in the internal jugular veins and veins of Rosenthal. But it is not always favorable.

\section{Ethical Approval}

All authors hereby declare that all experiments have been examined and approved by the appropriate ethics committee and have therefore been performed in accordance with the ethical standards laid down in the 1964 Declaration of Helsinki.

\section{References}

Abramova MF, Novoselova SN, Stepanova IA. Pokazateli normy i osobennosti provedeniya ultrazvukovyh issledovaniy brakhiotsefalnyh sosudov $\mathrm{u}$ detey v vozrastnom aspekte. [Indicators of norm and features of carrying out of brachiocephalic vessels researches at children in age aspect]. Detskiye bolezni serdtsa i sosudov, 2014; 4: 15-24 [in Russian].

Argyropoulou MI. Brain lesions in preterm infants: Initial diagnosis and follow-up. Pediatr Radiol, 2010; 40: 811-818.

Ashwal S, Russman BS, Blasco PA, Miller G, Sandler A, Shevell M, Stevenson R. Practice Parameter: Diagnostic assessment of the child with cerebral palsy: Report of the Quality Standards Subcommittee of the American Academy of Neurology and the Practice Committee of the Child Neurology Society. Neurology, 2004; 62: 851-863.

Benito Garcia M, Atin Arratibel MA, Terradillos Azpiroz ME. The Bobath concept in walking activity in chronic stroke measured through the international classification of functioning, disability and health. Physiother Res Int, 2015; 20(4): 242-250.

Bode $\mathrm{H}$, Buble R. Brain circulation in residual cerebral damage. A Doppler ultrasound study. Monatsschr Kinderheilkd, 1991; 139(3): 144-150.

Bortfeld SA. Lechebnaya fizicheskaya kultura i massazh pri detskom tserebralnom paraliche [Therapeutic physical culture and massage in children's cerebral palsy. M.: Meditsina. 1986. [in Russian].

Brooks J, Day S, Shavelle R, Strauss D. Low weight, morbidity, and mortality in children with cerebral palsy: New clinical growth charts. Pediatrics, 2011; 128: 299-307.

Bukhovets BO, Romanchuk AP. Bobath therapy in correction of psychomotor development of children with organic injuries CNS. Journal of Health Sciences, 2014; 4(6): 71-78.

Bukhovets BO. Control psychophysical children's development under the correction movement disorder. Journal of Education, Health and Sport, 2016; 6(2): 200-210.

Bukhovets BO, Romanchuk AP. The physical development of children with cerebral palsy in use of Bobat's method in physical therapy course. Physical Education, Sport, Kinesitherapy Research Journal, 2017; 2(3): 82-88.

Bukhovets BO, Romanchuk AP. Osoblyvosti zmin mozkovoho krovoobihu ditei $\mathrm{z}$ tserebralnym paralichem za vplyvu Bobat-terapii [Features of changes in cerebral blood circulation in children with cerebral palsy for the impact 
of Bobath therapy]. Visnyk Chernihivskoho natsional'noho pedahohichnoho universytetu imeni T. G. Shevchenka, 2017; 147 (I): 51-57. [in Ukrainian].

Dolgih GB, Ivanichev GA. Tserebralnye sosudistyye narusheniya $u$ detey $s$ detskim tserebralnym paralichom i sudorozhnym sindromom [Cerebral vascular disorders in children with cerebral spastic infantile paralysis and convulsive syndrome]. Kazanskiy meditsinskiy zhurnal, 2008; 89(3). [in Russian].

Evtushenko SK, Sazhneva IA, Yanovskaya NV. Sostoyanie mozgovoy gemodinamiki $\mathrm{u}$ detey $\mathrm{s}$ tserebralnyim paralichem i ego korrektsiya [State of cerebral hemodynamics for children with cerebral palsy and his correction]. Mizhnarodniy nevrologichniy zhurnal, 2014; 3 (65): 172-173 [in Russian].

Gialanella B, Benvenuti P, Santoro R. The painful hemiplegic shoulder: effects of exercise program according to Bobath. Clin Ther, 2004; 155: 491-497.

Homar J, Abadal JM, Llompart-Pou JA, Perez-Barcena J, Ibanez J. Cerebral hemodynamics in patients with traumatic brain injury evaluated by transcranial Doppler and transcranial color coded sonography. A comparison study, 2007; 18(3): 221.

Knox V, Evans AL. Evaluation of the functional effects of a course of Bobath therapy in children with cerebral palsy: A preliminary study. Dev Med Child Neurol, 2002; 44(7): 447-600.

Kozyavkin VI. Vozmozhnosti manual'noy terapii v neyromotornoy korrektsii statokineticheskikh narusheniy pri detskom tserebralnom paraliche [Possibilities of manual therapy in neuromotor correction of statokinetic disorders in children with cerebral palsy]. Voprosy kurortologii, fizioterapii i LFK, 1992; 1: 44-48 [in Russian].

Kraguljac D, Brencic M, Zibar T, Luke-Vrbanic TS. Habilitation of children with cerebral palsy. Medicina Fluminensis, 2018; 54(1): 6-17.

Lavrik SY Kliniko-neyrofiziologicheskiye i neyropsikhologicheskiye osobennosti narusheniy rechevogo razvitiya pri spasticheskikh formakh detskogo tserebral'nogo paralicha [Clinico-neurophysiological and neuropsychological features of speech development disorders in spastic forms of infantile cerebral palsy]. Aktualnye voprosy neyroreabilitatsii, 2004; 4: 107-113 [in Russian].

Fahey MC, Maclennan AH, Kretzschmar D, Gecz J, Kruer MC. The genetic basis of cerebral palsy. Developmental Medicine \& Child Neurology, 2016; 59(5): 462-469.

Nyankovsky SL, Pushnyk AI, Kuksenko OV. Osobennosti somaticheskoy patologii $\mathrm{u}$ detey $\mathrm{s}$ tserebral'nym paralichom [Peculiarities of somatic pathology in children with cerebral palsy]. Zdorove rebenka, 2017; 1: 54-62 [in Ukrainian].

Park EY, Kim WH. Effect of neurodevelopmental treatment-based physical therapy on the change of muscle strength, spasticity, and gross motor function in children with spastic cerebral palsy. J Phys Ther Sci, 2017; 29(6): 966-969.

Rosenkranz K, Langer R, Felix R. Transcranial Doppler sonography. Normal values and physiologic changes. Fortschr. Rüntgenstr, 1990; 152(3): 321 [in German].

Rosin YA. Dopplerografiya sosudov golovnogo mozga u detey [Dopplerography of cerebral vessels in children]. SPb. 2004. [in Russian].

Varadharajulu G, Shetty L, Sahoo K. The effect of bobath concept and conventional approach on the functional outcome in the post stroke hemiplegic individuals. Journal of Sports and Physical Education, 2017; 4 (2): 10-14.

Vargus-Adams JN, Majnemer A. International Classification of Functioning, Disability and Health (ICF) as a framework for change: revolutionizing rehabilitation. J Child Neurol, 2014; 29(8): 1030-1035.

Vaughan-Graham J, Cott C, Wright FV. The Bobath (NDT) concept in adult neurological rehabilitation: what is the state of the knowledge? A scoping review. Part I: conceptual perspectives. Disabil Rehabil, 2015; 37(20): 1793-1807.

Vaughan-Graham J, Cott C, Wright FV. The Bobath (NDT) concept in adult neurological rehabilitation: what is the state of the knowledge? A scoping review. Part II: intervention studies perspectives. Disabil Rehabil, 2015; 37(21): 1909. 